\title{
Pemecahan Masalah Stabilitas Abutment dan Oprit Jembatan di Atas Tanah Lunak Menggunakan Relieving Platform
}

\author{
Nabilla Zahera ${ }^{1, *}$, Indrasurya B. Mochtar ${ }^{1}$, Trihanyndio Rendy Satrya ${ }^{1}$ \\ Departemen Teknik Sipil, Institut Teknologi Sepuluh Nopember ${ }^{1}$ \\ Koresponden*,Email: zaheranabilla@gmail.com
}

\begin{tabular}{|c|c|c|}
\hline & Info Artikel & Abstract \\
\hline Diajukan & 26 Juni 2021 & The problem that often occurs in the design of bridges built on soft soil is excessive horizontal \\
\hline Diperbaiki & 22 Juli 2021 & movement of the abutments. To deal with this condition, the planner changed the construction \\
\hline Disetujui & 22 Juli 2021 & $\begin{array}{l}\text { to slab on piles. It's just that the addition of construction will increase costs so it is less effective } \\
\text { and requires alternative methods. An effective alternative method is to use a release platform } \\
\text { and posts mounted behind the supports. The bridge oprite was analyzed on layered soft soil } \\
\text { with very soft, soft, and medium consistency. The results of the study at an altitude }(4 \mathrm{~m} \text { to } 12 \mathrm{~m}) \text {, } \\
\text { oprit experienced the possibility of landslides }(S F \leq 1) \text {. In the calculation analysis, the pile is } \\
\text { given a variation in diameter; } 30 \mathrm{~cm}, 50 \mathrm{~cm} \text { and } 60 \mathrm{~cm} \text {; class } C \text { type; the distance between } 2.5 D \\
\text { and } 3 D \text { poles to determine the most effective system. The results showed that the most effective }\end{array}$ \\
\hline $\begin{array}{l}\text { Keywords: } \\
\text { stability, } p\end{array}$ & $\begin{array}{l}\text { ing platform, overall } \\
\text { utment }\end{array}$ & $\begin{array}{l}\text { construction at a height }(4 \mathrm{~m} \text { to } 12 \mathrm{~m}) \text { was at a distance of } 2.5 \mathrm{D} ; 30 \mathrm{~cm} \text { diameter. Although it } \\
\text { produces a greater number of poles, it results in a much cheaper additional cost. }\end{array}$ \\
\hline
\end{tabular}

Abstrak

Permasalahan yang sering terjadi pada perencanaan jembatan yang dibangun pada tanah lunak adalah pergerakan yang berlebihan secara horizontal pada abutment. Menyiasati kondisi tersebut, perencana mengganti konstruksi menjadi slab on piles. Hanya saja penambahan konstruksi tersebut akan menambah biaya sehingga kurang efektif dan memerlukan metode alternatif. Metode alternatif yang efektif adalah menggunakan relieving platform dan tiang-cerucuk yang dipasang di belakang abutment. Oprit jembatan dianalisis pada pada tanah lunak berlapis dengan konsistensi very soft, soft, dan medium. Hasil penelitian pada ketinggian ( $4 \mathrm{~m} \mathrm{~s} / \mathrm{d} 12 \mathrm{~m}$ ), oprit mengalami kemungkinan kelongsoran (SF $\leq$ 1). Pada analisis perhitungan, tiang diberi variasi diameter; $30 \mathrm{~cm}, 50 \mathrm{~cm}$, dan $60 \mathrm{~cm}$; tipe kelas C; jarak antar tiang 2,5D dan 3D untuk mengetahui sistem yang paling efektif. Hasil penelitian menunjukkan konstruksi yang paling efektif pada ketinggian $(4 \mathrm{~m} / \mathrm{s} / \mathrm{d} \mathbf{~} \mathrm{m})$ adalah pada jarak 2,5D; diameter $30 \mathrm{~cm}$. Walaupun menghasilkan jumlah tiang yang lebih

Kata kunci: relieving platform overall banyak tetapi menghasilkan tambahan biaya yang jauh lebih murah.

stability, cerucuk, abutment

Pada banyak kasus yang terjadi di lapangan, ada kondisi

\section{Pendahuluan}

Di Indonesia, sering kali terjadi permasalahan pada abutment jembatan terutama bila tanah dasar pada timbunan tersebut merupakan jenis tanah lunak. Permasalahan yang paling sering terjadi adalah terjadinya pergerakan yang berlebihan secara horizontal pada abutment (arah pergerakan ke depan abutment) saat tanah urugan di belakang abutment mulai dilakukan pengurugkan, atau terjadinya kelongsoran pada timbunan beberapa waktu setelah timbunan oprit jembatan selesai diurugkan. Kondisi ini timbul karena jembatan tersebut dibangun diatas tanah lunak yang mungkin tidak kuat menahan beban diatasnya sehingga cenderung longsor ke arah sungai. Hal ini mengakibatkan secara overall stability, tanah dasar tidak kuat menahan beban tanah timbunan oprit jembatan di belakang abutment [1]. Ilustrasi kelongsoran ini dapat diberikan pada Gambar 1 yang merupakan timbunan oprit jembatan yang baru saja dilakukan penimbunan di belakang jembatan [1]. dimana keruntuhan tidak terlihat; hanya abutment dan tiang pondasi jembatannya saja yang bergerak maju secara berlebihan. Kondisi lainnya merupakan abutment yang bergerak hingga terjadi keruntuhan. Pada kondisi ini, umumnya pekerjaan jembatan yang mengalami hal tersebut tidak lagi dapat diteruskan karena kondisi yang terjadi di lapangan sudah menyimpang dari desain awalnya. Contoh kondisi menyimpang yang terjadi adalah bentang jembatan yang sudah tidak lagi memenuhi syarat, pondasi tiang pancang melengkung atau patah, abutment jembatan bergeser dari posisi yang direncanakan semula, dan lain sebagainya. Kondisi tersebut menyebabkan pekerjaan jembatan harus dihentikan dan memerlukan desain ulang pada abutment. Hal ini tentunya dapat menyebabkan kerugian yang sangat besar bagi setiap proyek jembatan yang terkena masalah di atas, baik kerugian dari segi kemunduran waktu maupun segi biaya. 
Hal di atas dapat terjadi karena pada saat mendesain jembatan, umumnya permasalahan overall stability pada oprit jembatan di belakang abutment tidak diperhatikan. Perencana hanya melihat pedoman perencanaan jembatan yang selama ini memperhitungkan kestabilan dari abutment akibat gayagaya yang bekerja pada jembatan (struktur atas), gaya aktif akibat tekanan tanah urug di belakang abutment serta gayagaya yang timbul pada saat terjadi gempa.

Menyiasati kondisi tanah dasar yang lunak, banyak perencana abutment jembatan mengganti konstruksi abutment jembatan menjadi konstruksi slab on piles. Perencanaan tersebut dibuat sedemikian rupa sampai tinggi jembatan dari muka tanah asli $(=\mathrm{H})$ cukup rendah sehingga tanah dasarnya sudah mampu mendukung beban timbunan oprit jembatan. Hanya saja, konstruksi slab on piles akan menambah biaya jembatan secara signifikan. Berdasarkan alasan tersebut, maka diperlukan suatu alternatif yang dapat memberikan nilai yang lebih ekonomis serta dapat menangani kestabilan abutment.

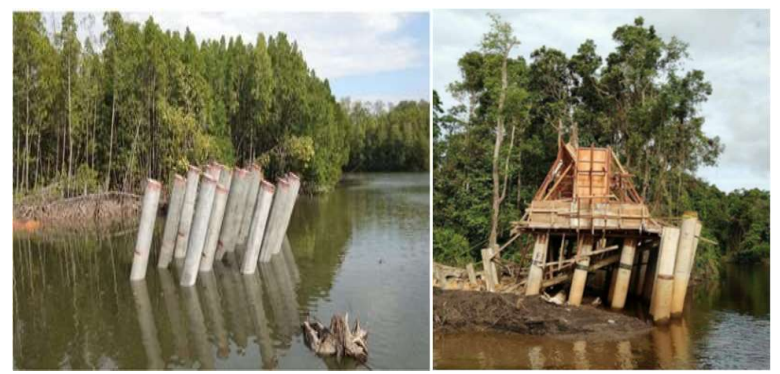

Gambar 1. Kondisi Abutment Jembatan yang sudah mengalami Kemiringan ke arah Sungai aaat Tanah Urugan untuk Oprit Jembatan Mulai Diletakkan [1]

Salah satu metode alternatif yang paling efektif untuk mengatasi permasalahan tersebut adalah menggunakan relieving platform yang dipasang di belakang abutment. Platform tersebut berupa pelat beton yang ditopang oleh pondasi tiangtiang yang juga berfungsi sebagai cerucuk yang diilustrasikan pada Gambar 2.

Penggunaan pondasi tiang di bawah platform sebagai cerucuk dimaksudkan untuk memberikan tambahan tahanan geser sehingga meningkatkan overall stability dari tanah oprit timbunan jembatan dalam arah longitudinal. Pemasangan tiang sebagai cerucuk dipasang hingga memotong garis kelongsoran. Sedangkan penggunaan relieving platform, berfungsi untuk menghilangkan sebagian dari beban timbunan tanah oprit jembatan (beban tanah ABCD pada agar tidak membebani tanah asli yang merupakan tanah lunak di bawahnya seperti yang terlihat pada Gambar 3 .

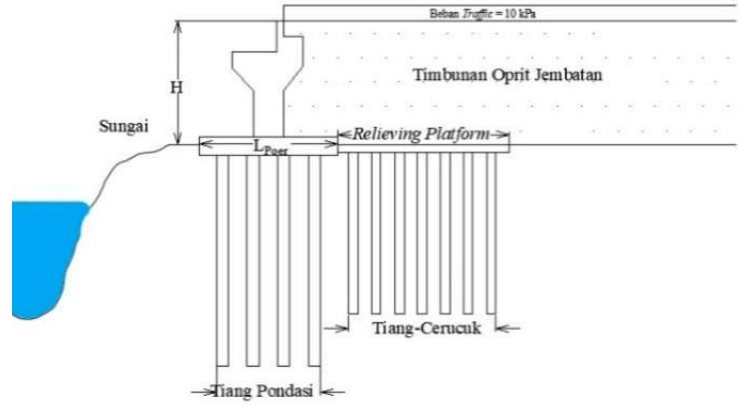

Gambar 2. Ilustrasi Relieving Plaform di Belakang Abutment

Beban tanah timbunan oprit jembatan ABCD didukung oleh tiang cerucuk di bawah platform yang memiliki kedalaman tiang yang mencukupi, sehingga beban aksial yang bekerja pada setiap tiang di bawah platform harus $\leq \mathbf{P}_{\mathbf{i j i n}}$ dari 1 tiang. Selain itu, tiang-tiang tersebut juga harus kuat menahan gaya geser lateral/kesamping yang diakibatkan oleh adanya kecenderungan tanah lunak di belakang platform (pada bagian sebelah kanan garis BC pada Gambar 4. Untuk perhitungan overall stability dari abutment jembatan dengan adanya relieving platform di belakang abutment, ada 2 (dua) asumsi besar yang dapat digunakan [1] yaitu:

1. Asumsi A, yaitu asumsi bahwa pondasi tiang dari abutment jembatan juga ikut berfungsi dalam menjaga overall stability dari abutment jembatan, relieving platform dan pondasi tiang-tiangnya hanya sebagai perkuatan tambahan saja untuk membuat Angka Keamanan (= Safety Factor $=\mathrm{SF}$ ) dari overall stability menjadi $\geq \mathrm{SF}_{\text {aman }}$

2. Asumsi B, yaitu asumsi bahwa pondasi dari abutment jembatan hanya untuk menahan beban-beban yang langsung bekerja pada jembatan saja. Overall stability dari abutment sepenuhnya dipikul oleh relieving platform yang sengaja dibangun untuk menjaga overall stability dari abutment jembatan.

Pada penelitian ini, asumsi yang dipilih adalah Asumsi B atas dasar pertimbangan sebagai berikut:

a. Abutment akan selalu lebih aman bila didesain dengan Asumsi B dari pada didesain dengan Asumsi A.

b. Jika desain dilakukan berdasarkan Asumsi A, maka tidak dapat dipastikan adanya pembagian kekuatan antara pondasi tiang dari abutment dan tiang cerucuk dari relieving platform.

c. Asumsi B membebaskan perencana untuk merencanakan pondasi abutment jembatan terlebih dahulu karena perencanaan relieving platform dapat dilakukan secara terpisah

d. Jika digunakan Asumsi A, tambahan pergerakan pondasi abutment akibat desakan ke depan oleh tanah lunak di dasar oprit jembatan sangat sulit untuk diperkirakan. 
Walaupun perhitungan overall stability (dengan Asumsi A) memenuhi syarat, belum tentu abutment jembatan tersebut tetap aman dalam jangka panjang.

Sehingga jika memerlukan perencanaan struktur penguat berupa relieving platform di belakang abutment jembatan, maka segmen tanah $\mathrm{ABCD}$ diatas relieving platform dianggap tidak ada, seperti yang diilustrasikan pada Gambar 4.

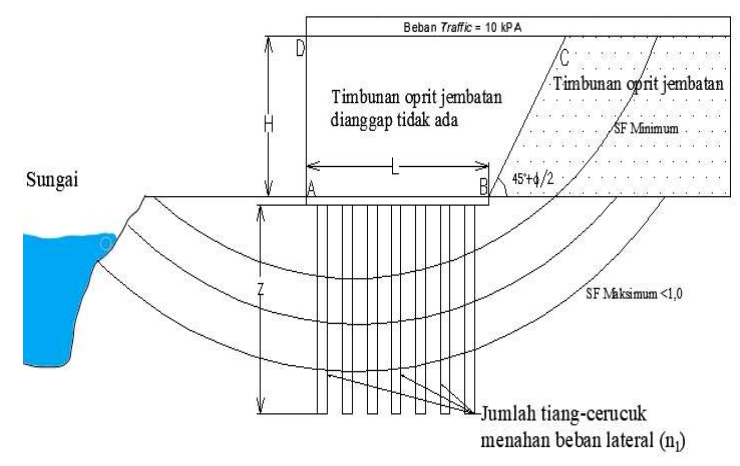

Gambar 3. Ilustrasi Relieving Plaform dan Tiang-Cerucuk Menahan Overall Stability

Jika digunakan tiang-tiang sebagai cerucuk dengan diameter tiang tertentu, jumlah tiang-cerucuk yang diperlukan untuk menjaga overall stability dalam arah longitudinal $\left(\mathrm{n}_{1}\right)$ pada Gambar 3 merupakan jumlah per meter lebar badan jalan arah melintang). Jumlah ini perlu disesuaikan dengan jumlah tiang pancang yang dibutuhkan untuk memikul beban tanah ABCD + beban lalu-lintas per lebar 1 meter jalan $\left(\mathrm{n}_{2}\right)$, sebagaimana yang dapat diilustrasikan pada Gambar 4.

Selama ini, perencana sering menghadapi tantangan untuk mendesain dinding penahan tanah dengan perbedaan ketinggian. Dinding penahan tahan yang sering didesain adalah dinding penahan tanah dengan kantilever, dinding penahan dengan counterfort dan dinding penahan dengan relieving platform. Dari ketiga dinding penahan tersebut dilakukan sebuah studi perbandingan dan alternatif dengan estimasi biaya paling rendah dipilih sebagai solusi dan desain terbaik. Penelitian tersebut menunjukkan bahwa penggunaan dinding penahan menggunakan relieving platform merupakan solusi terbaik dan terbukti lebih efektif [2]. Selain itu, relieving platform pada dinding penahan meningkatkan stabilitas terhadap faktor keamanan pada sliding dan overturning hampir dua kali lipat [3]. Dinding penahan tahan untuk ketinggian diatas $10 \mathrm{~m}$ memerlukan desain dinding penahan tanah yang lebih ekonomis. Solusi terbaik adalah menggunakan relieving platform dan dibentuk sederhana atau terikat antara dinding penopang yang mungkin didukung oleh kolom atau pilar [4].

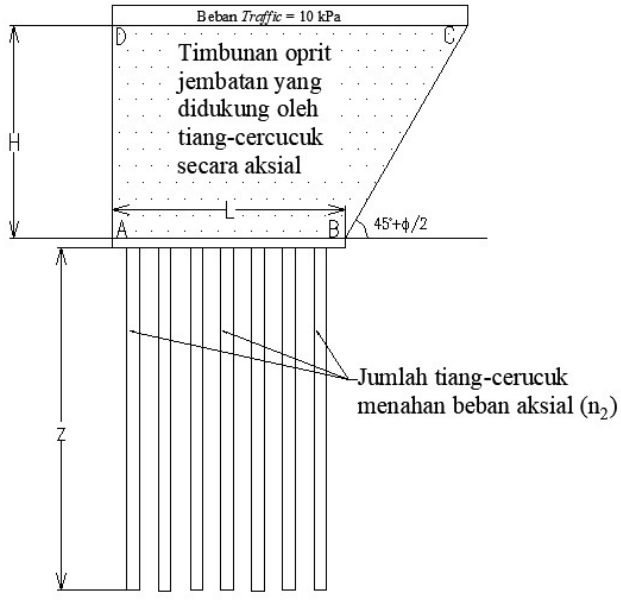

Gambar 4. Ilustrasi Pondasi Tiang di Bawah Relieving Platform untuk Mendukung Beban Oprit Jembatan Secara Aksial

Berdasarkan ulasan yang disajikan di atas, penggunaan relieving platform tentunya sangat tepat sebagai penanganan kelongsoran yang ditimbulkan akibat overall stability. Hal ini karena pendistribusian gaya-gaya yang mendorong abutment akan diterima oleh relieving platform sehingga abutment hanya akan menopang struktur jembatan dan beban yang bekerja di atasnya. Oleh karena itu, penting dilakukan penelitian perencanaan relieving platform yang dipasang di belakang abutment menggunakan tiang yang bekerja sebagai pondasi untuk pendistibusian beban aksial dan asumsi overall stability arah memanjang jalan (longitudinal). Analisis dilakukan pada ketinggian oprit jembatan yang umumnya dimulai dari ketinggian $4 \mathrm{~m} \mathrm{~s} / \mathrm{d} 12 \mathrm{~m}$ dengan berbagai variasi. Variasi yang digunakan pada penelitian ini adalah ukuran diameter tiang dan jarak antar tiang untuk mengetahui sistem relieving platform dan tiang cerucuknya yang paling efektif.

\section{Metode}

Pengumpulan Data Sekunder

Data yang digunakan untuk penelitian ini adalah data sekunder dengan parameter-parameter yang diasumsikan yaitu angka pori $\left(\mathrm{e}_{\mathrm{o}}\right)$ dengan rentang 1,3-1,8, specific gravity $(\mathrm{Gs})$ dengan nilai 2,6 , liquid limit (LL) dengan nilai $70 \%$ dan plastic limit (LL) dengan nilai 40\% [5].

\section{Analisis Overall Stability dengan Program Bantu XSTABL}

Analisis overall stability dilakukan untuk mengetahui apakah tanah dasar dan timbunan tersebut mengalami kelongsoran yang mencapai tanah dasar atau tidak. Jika pada 
saat pengecekan overall stability didapatkan ( $\mathrm{SF} \leq 1)$, maka timbunan dan tanah dasar tersebut memerlukan perkuatan relieving platform dan tiang-cerucuk yang dipasang di belakang abutment. Namun jika saat pengecekan overall stability didapatkan nilai aman ( $\mathrm{SF} \geq 1)$, maka tanah dasar dan oprit jembatan dinyatakan aman terhadap overall stability dan tidak memerlukan perkuatan relieving platform.

\section{Hasil Perhitungan Kebutungan Relieving Platform Bersama Tiang-Cerucuk}

Penentuan kebutuhan relieving platform dan tiang cerucuk memerlukan asumsi beban secara aksial dan lateral. Kebutuhan relieving platform nantinya mengikuti jumlah cerucuk dalam menerima kedua asumsi beban tersebut. Kebutuhan jumlah tiang menahan beban secara lateral perlu menentukan tambahan momen perlawanan, menghitung momen lentur, menghitung gaya horizontal yang ditahan satu tiang dan menentukan kedalaman tiang untuk cerucuk pada $\mathrm{SF} \leq$ [6]. Pada kebutuhan tiang menahan beban secara aksial perlu menghitung tahahan ujung pondasi tiang, tahanan geser selimut tiang dan daya dukung ijin aksial tiang pada SF 2,5 [7].

Ringkasan Konstruksi Relieving Platform Bersama TiangCerucuk Pada Berbagai Ketinggian Oprit Jembatan

Ringkasan dari berbagai variasi dimuat pada tabel dan grafik yang dapat mempermudah perencanaan relieving platform dan tiang-cerucuk di belakang abutment dengan beberapa parameter. Hasil yang akan didapatkan adalah sebagai berikut:

a. Kebutuhan lebar relieving platform

b. Kebutuhan jumlah tiang-cerucuk

c. Kedalaman tiang-cerucuk

\section{Analisis Tambahan Biaya Perkuatan Relieving Platform} Bersama Tiang-Cerucuk

Analisis biaya diperlukan untuk mengetahui berapa biaya yang dibutuhkan pada perencanaan perkuatan relieving platform bersama dengan tiang-cerucuknya pada masing-masing variasi ketinggian oprit jembatan. Analisis tambahan biaya yang dihitung merupakan tambahan biaya pemancangan tiang, pekerjaan plat beton bertulang dan harga tiang spun pile.

\section{Hasil dan Pembahasan}

\section{Parameter Data Tanah}

Penelitian ini menggunakan jenis tanah lunak berlapis dengan konsistensi very soft (sangat lunak), soft (lunak) dan medium (sedang). Tanah dasar lunak tersebut belum mengalami konsolidasi (kondisi normally consolidated, NC, soil). Nilai kohesi tanah diperoleh dengan perumusan sebagai berikut [8],

Untuk PI $\leq 100 \%$ maka,

$c_{u}\left(\frac{\mathrm{kg}}{\mathrm{cm}^{2}}\right)=0,0737+\left(0,19-16 \times 10^{-4} \times P I\right) \times P o^{\prime}$

Untuk PI $\geq 100 \%$ maka,

$c_{u}\left(\frac{\mathrm{kg}}{\mathrm{cm}^{2}}\right)=0,0737+\left(0,045-4 \times 10^{-5} \times P I\right) \times P o^{\prime}$

Nilai N-SPT pada tanah dapat menggunakan korelasi NSPT dan konsistensi tanah untuk tanah dominan lanau dan lempung [9].

Data tanah yang digunakan merupakan data asumsi yang mengacu pada parameter-parameter sesuai kondisi lapangan. Parameter yang diasumsikan yaitu angka pori $\left(e_{o}\right)$, specific gravity $(G s)$, liquid limit $(L L)$, dan plastic limit $(P L)$.

Nilai tersebut menghasilkan beberapa parameter lainnya seperti berat volume jenuh $\left(\gamma_{\text {sat }}\right)$, plastic limit $(\mathrm{PL})$, sehingga akan didapatkan tegangan overburden efektif $\left(\sigma_{\mathrm{o}}^{\prime}\right)$, tegangan prakonsolidasi $\left(\sigma_{\mathrm{p}}^{\prime}\right)$ dengan hfluktuasi $=1,5$ meter, serta kohesi $\left(\mathrm{C}_{\mathrm{u}}\right)$.

\section{Stabilitas Timbunan}

Dalam setiap keadaan, tanah yang tidak datar akan menghasilkan komponen gravitasi dari berat yang menggerakkan massa tanah dari elevasi lebih tinggi ke elevasi lebih rendah. Faktor keamanan pada stabilitas timbunan dapat dihitung menggunakan rumus sebagai berikut,

$S F=\frac{\tau_{f}}{\tau_{m}}$

dimana:

$\mathrm{SF} \quad=$ faktor keamanan (safety factor)

$\tau_{f} \quad=$ kekuatan geser rata-rata dari tanah

$\tau_{m} \quad=$ kekuatan yang bekerja sepanjang bidang longsor

Dalam menganalisis timbunan, penulis menggunakan program bantu XSTABL, dimana perhitungan keamanan lereng dilakukan dengan metode irisan (Modified Bishop Method). Analisis overall stability terkritis yang dihasilkan oleh program bantu XSTABL pada berbagai ketinggian oprit jembatan dapat dilihat pada Tabel 1.

Berdasarkan hasil analisis, nilai safety factor kritis pada berbagai ketimbunan menghasilkan $\mathrm{SF}<1$. Hal tersebut menunjukkan bahwa tanah dasar dan timbunan tersebut kemungkinan dapat mengalami kelongsoran $(\mathrm{SF} \leq 1)$, sehingga memerlukan perkuatan. Hasil yang diperoleh pada Tabel 1 merupakan analisis overall stability dengan SF terkritis pada 10 kali iterasi. Hal tersebut dilakukan dengan mengubahubah kedudukan jari-jari kelongsoran untuk beberapa harga 
dengan cara mencoba-coba. Langkah tersebut dilakukan untuk dapat mencari perkuatan tiang-cerucuk terbanyak yang dapat mencakup seluruh kemungkinan kelongsoran.

Setelah dilakukan pengecekan overall stability pada ketinggian timbunan oprit jembatan lainnya, hasil yang didapatkan adalah timbunan oprit jembatan mengalami kemungkinan kelongsoran $(\mathrm{SF} \leq 1)$. Hal tersebut menyebabkan perlunya perkuatan pada seluruh ketinggian timbunan oprit jembatan tersebut.

Tabel 1. Analisis Overall Stability

\begin{tabular}{cccccc}
\hline $\mathrm{H}$ & FOS & \multicolumn{2}{c}{ Circle Center } & Radius & $\begin{array}{c}\text { Resisting } \\
\text { (coord }-\mathrm{m})\end{array}$ \\
$(\mathrm{m})$ & $($ Bishop $)$ & $(\mathrm{x})$ & $(\mathrm{y})$ & $(\mathrm{m})$ & $(\mathrm{kN}-\mathrm{m})$ \\
\hline 4 & 0,944 & 89,54 & 29,43 & 13,41 & 4606 \\
6 & 0,705 & 90,48 & 30,38 & 14,75 & 6353 \\
8 & 0,557 & 93,8 & 33,03 & 18,98 & 11750 \\
10 & 0,488 & 93,64 & 34,2 & 21,17 & 15890 \\
12 & 0,431 & 94,1 & 33,38 & 19,44 & 14280 \\
\hline
\end{tabular}

\section{Perencanaan Cerucuk}

Penggunaan cerucuk bertujuan untuk meningkatkan tahanan geser tanah. Kekuatan tahanan 1 cerucuk terdapat faktor koreksi sebagai berikut [10],

$P_{\text {maks }}=\frac{M_{\text {maks }}}{F_{m} \times T} \times F_{k}$

dimana nilai $F_{k}$ adalah,

$F_{k}=2,643 \times\left[\frac{0,89+, 12\left(\frac{L}{D}\right)}{2,69}\right] \times\left[\frac{0,855 \times\left(C_{u}^{-0,392}\right)}{2,865}\right]$

Sehingga dari perhitungan keseluruhan di atas didapatkan hasil sebagai berikut:

$$
\begin{array}{ll}
\text { - } \quad \mathrm{P}_{\text {maks } 1 \text { cerucuk }} & =112,548 \mathrm{kN} \\
& =11,255 \mathrm{ton} \\
\text { - } \quad \text { Jumlah cerucuk } & =1 \mathrm{buah} \\
\quad \text { Jumlah cerucuk minimal } & =2 \mathrm{buah} \\
\text { - Kedalaman cerucuk } & =10 \text { meter }
\end{array}
$$

Kedalaman cerucuk diperoleh berdasarkan bidang longsor terdalam ditambah dengan 3 meter di bawah bidang longsor. Bidang longsor terdalam pada percobaan relieving platform di atas adalah 6,21 meter dan jika ditambah 3 m adalah $=9,21$ meter $\approx 10$ meter. Kedalaman tiang ditambah dengan 3 meter bertujuan sebagai kedalaman tancapan tiang agar dapat memotong bidang kelongsoran mencapai safety factor rencana. Perhitungan diulangi untuk ketinggian oprit timbunan jembatan lainnya.

Selain berfungsi untuk menahan overall stability, tiang cerucuk juga bekerja sebagai tiang pondasi yang berfungsi mendistribusikan beban vertikal.

\section{Pondasi Tiang Pancang}

Tiang pancang adalah bagian-bagian konstruksi yang digunakan untuk mentransmisikan beban-beban permukaan ke tingkat-tingkat permukaan yang lebih rendah dalam massa tanah. Hal ini merupakan distribusi vertikal dari beban sepanjang poros tiang-pancang atau pemakaian beban secara langsung terhadap lapisan yang lebih rendah melalui ujung tiangpancang. Tiang pancang seringkali digunakan untuk melihat pergerakan tanah, seperti longsoran pada tanah [11]. Untuk dapat mendesain kebutuhan tiang, maka terlebih dahulu menentukan kapasitas daya dukung tiang dalam menerima beban.

Kapasitas ultimit tiang dapat dihitung secara empiris dari nilai $N$ pada nilai N-SPT. Untuk perhitungan tersebut dapat menggunakan beberapa metode. Metode yang digunakan untuk menentukan daya dukung tiang pada penelitian ini adalah metode Meyerhof [11] sebagai berikut,

$Q_{u l t}=40 \times \bar{N} \times A_{p}+\sum C l_{i} \times A s_{i}$

Daya dukung satu tiang pancang dalam grup dapat ditentukan dengan mengalikan daya dukung 1 tiang pancang dan efisiensi tiang. Nilai effisiensi tiang pancang grup dapat ditentukan berdasarkan persamaan Converse-Labarre sebagai berikut,

$E_{g}=1-\frac{\arctan \left(\frac{d}{s}\right)}{90^{\circ}} \times\left(2-\frac{1}{m}-\frac{1}{n}\right)$

Berikut merupakan contoh perhitungan effisiensi tiang pada ketinggian timbunan $4 \mathrm{~m}$ dengan perencanaan lebar $2 \mathrm{~m}$ arah longitudinal,

Diameter tiang cerucuk (d) $\quad=60 \mathrm{~cm}=0,6 \mathrm{~m}$

Jarak antar tiang cerucuk $(\mathrm{s}) \quad=1,5 \mathrm{~m}$

Jumlah baris (m) = 1 buah

Jumlah kolom (n) = 2 buah

$E_{g}=1-\frac{\arctan \left(\frac{0,6}{1,5}\right)}{90^{\circ}} \times\left(2-\frac{1}{1}-\frac{1}{2}\right)=0,879$

Sehingga daya dukung ijin grup effisiensi pada kedalaman 10 meter adalah

$\mathrm{P}_{\mathrm{ijin} \text { effisiensi }}=\mathrm{P}_{\mathrm{ijin}} \times E_{g}=24,82 \times 0,879=21,817$ ton

Kebutuhan jumlah tiang dan lebar relieving platform harus dilakukan pengecekkan terlebih dahulu apakah telah memenuhi persyaratan. Berikut merupakan langkah-langkah pengecekan lebar relieving platform dan kebutuhan tiang,

a. Cek lebar relieving platform dan jumlah tiang

Lebar relieving platform yang dihitung adalah $2 \mathrm{~m}$. Untuk dapat bekerja secara maksimal, tiang membentuk grup dan memerlukan lebar tepi. Sehingga lebar relieving platform perlu adalah sebagai berikut, 


$$
\begin{aligned}
\text { Lebar platform perlu } & =s \times(\mathrm{n}-1)+(3 \times D) \\
& =1,5+(2-1)+(3 \times 0,6) \\
& =3,3 \text { meter. }
\end{aligned}
$$

Sehingga lebar platform menjadi 3,3 meter.

b. Cek daya dukung grup ( $\left.\mathrm{Q}_{\text {grup }}\right)$ dan total beban vertikal (V) $Q_{\text {grup }}$ harus lebih besar dari total beban vertikal (V) atau $\mathrm{Q}_{\text {grup }}>\mathrm{V}$. Untuk dapat mencari daya dukung grup dapat menggunakan perumusan berikut ini,

$$
\begin{array}{ll}
Q_{\text {grup }} & =E_{g} \times n \times Q_{\text {tiang }} \\
Q_{\text {grup }} & =0,879 \times(7 \times 2) \times 24,82=305,43 \text { ton } \\
V & =483,99 \text { ton } \\
Q_{\text {grup }}>\mathrm{V} & =\text { Belum memenuhi }
\end{array}
$$

Sehingga kedalaman tiang perlu ditambah. hingga $Q_{\text {grup }}$

$>\mathrm{V}$, kedalaman perlu ditambah sebanyak 10 meter dan mendapatkan kedalaman total sebesar 20 meter. Berdasarkan penambahan kedalaman tiang tersebut, maka,

$$
\begin{aligned}
& Q_{\text {grup }}=0,879 \times(7 \times 2) \times 40,33=496,223 \text { ton } \\
& V \quad=483,99 \text { ton } \\
& Q_{\text {grup }}>\mathrm{V}=\text { Memenuhi }
\end{aligned}
$$

c. Cek daya dukung ijin maksimum $\left(\mathrm{P}_{\text {maks }}\right)$ dan daya dukung ijin effisiensi tiang $\left(\mathrm{P}_{\mathrm{ijin}}\right.$ effisiensi $)$

Berikut merupakan hasil perhitungan $\mathrm{P}_{\text {maks }}$ dan $\mathrm{P}_{\mathrm{ijin} \text { effisiensi }}$ pada kedalaman 10 meter,

$$
\begin{aligned}
P_{\text {maks }}=\frac{V}{n}= & \frac{483,99}{(2 \times 7)}=34,57 \text { ton } \\
P_{i j i n ~ e f f i s i e n s i} & =P_{i j i n-10 m} \times E_{g} \\
& =24,82 \times 0,879=21,817 \text { ton }
\end{aligned}
$$

$P_{i j \text { in effisiensi }} \geq P_{\text {maks }}=$ belum memenuhi, sehingga kedalaman tiang cerucuk perlu ditambah. Dalam beberapa kali perhitungan kedalaman tiang kedalaman perlu 10 m. Pada kedalaman 20 meter memenuhi kedua kontrol tersebut. Berikut merupakan hasil perhitungan $\mathrm{P}_{\text {maks }}$ dan $\mathrm{P}_{\mathrm{ijin}}$ effisiensi pada kedalaman 20 meter,

$$
\begin{aligned}
P_{\text {maks }} & =\frac{V}{n}=\frac{483,99}{(2 \times 7)}=34,57 \text { ton } \\
P_{i j i n \text { effisiensi }} & =P_{i j i n-20 \mathrm{~m}} \times E_{g} \\
& =40,33 \times 0,879=35,44 \text { ton }
\end{aligned}
$$

\section{Penentuan Kebutuhan Jumlah Tiang}

Hal yang perlu diperhatikan selanjutnya adalah menentukan apakah kebutuhan lateral $\left(\mathrm{n}_{1}\right)$ dan aksial $\left(\mathrm{n}_{2}\right)$ mendapatkan jumlah kebutuhan cerucuk yang sama. Jika pada saat pengecekan kebutuhan cerucuk dalam menerima beban aksial dan lateral belum didapatkan kebutuhan cerucuk yang sama, maka dapat dilakukan dengan ketentuan sebagai berikut:

a. Jika $\left(\mathrm{n}_{1}\right)<\left(\mathrm{n}_{2}\right)$, maka lebar relieving platform perlu di tambah

b. Jika $\left(\mathrm{n}_{1}\right)>\left(\mathrm{n}_{2}\right)$, maka lebar relieving platform dikurangi
Hasil analisis dari kedua beban tersebut dapat dilihat pada Tabel 2. Berdasarkan analisis pada Tabel 2, kebutuhan lebar relieving platform dan tiang cerucuk memenuhi persyaratan yang diberikan. Dimana kebutuhan lebar relieving platform dan jumlah tiang yang sama mampu menahan beban yang diberikan secara lateral dan aksial. Kedalaman tiang yang diambil merupakan kedalaman maksimum dari asumsi kedua beban.

Tabel 2. Hasil Analisis Kebutuhan Tiang Lateral dan Lebar Platform Dalam Menahan Beban Lateral dan Aksial

\begin{tabular}{lcc}
\hline \multicolumn{1}{c}{ Parameter } & $\begin{array}{c}\text { Asumsi Menahan } \\
\text { Beban Lateral }\end{array}$ & $\begin{array}{c}\text { Asumsi Menahan } \\
\text { Beban Aksial }\end{array}$ \\
\hline $\begin{array}{l}\text { Jumlah tiang } \\
\text { (n) }\end{array}$ & 2 buah & 2 buah \\
$\begin{array}{l}\text { Kedalaman } \\
\text { tiang (d) }\end{array}$ & 10 meter & 20 meter \\
$\begin{array}{l}\text { Lebar } \\
\text { platform (L) }\end{array}$ & 3,3 meter & 3,3 meter \\
\hline
\end{tabular}

Hasil Kebutuhan Relieving Platform Bersama Tiang Cerucuk Dengan berbagai Variasi

Ringkasan konstruksi relieving platform dan tiangcerucuk dimuat dalam bentuk tabel dan grafik untuk mempermudah perencanaan relieving platform dan tiang-cerucuk di belakang abutment. Ilustrasi potongan tegak untuk perencanaan relieving platform dan tiang-cerucuk di belakang abutment jembatan dan ilustrasi ilustrasi relieving platform dan tiang-cerucuk tampak atas dapat dilihat pada Gambar 5. Namun perencana perlu meninjau kembali kedalaman tiang yang akan digunakan. Hal ini berkaitan dengan jenis tanah dasar yang akan digunakan dalam perencanaan relieving platform dan tiang cerucuknya.

Penelitian ini menggunakan data tanah dasar lunak dengan asumsi kedalaman 30 meter. Kondisi tanah dasar lunak tersebut merupakan jenis tanah normally consolidated (NC soil) dengan konsistensi very soft (sangat lunak) dengan ketebalan 3 meter, soft (lunak) dengan ketebalan 14 meter, dan medium dengan ketebalan 13 meter. Jika pada saat perencanaan relieving platform di lapangan didapatkan kedalaman tanah keras yang kurang dari hasil kedalaman pada penelitian, maka pemancangan tiang-cerucuk hanya sampai pada kedalaman tanah keras saja.

Ringkasan konstruksi dapat dilihat pada Tabel 3 hingga Tabel 8. Grafik hubungan tinggi timbunan oprit jembatan dan jumlah tiang-cerucuk dapat dilihat pada Gambar 6 dan Gambar 7, sedangkan grafik hubungan tinggi timbunan oprit jembatan dan kebutuhan lebar relieving platform dapat dilihat pada Gambar 8 dan Gambar 9. 


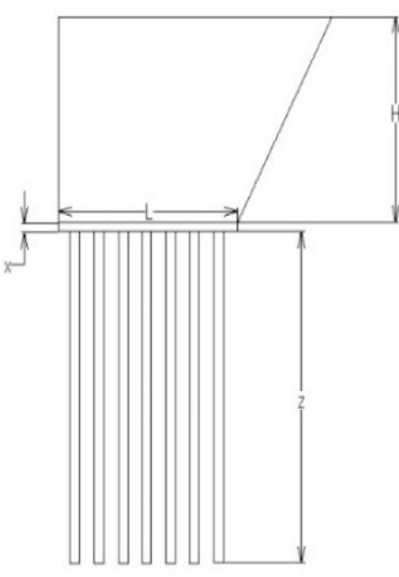

(a)

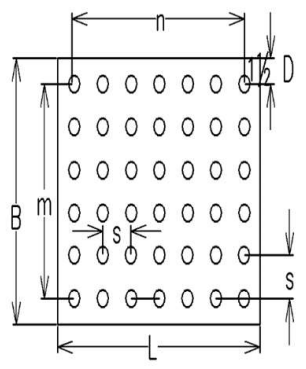

(b)
Gambar 5. (a) Potongan Tegak Relieving Platform dan Tiang Cerucuknya; (b) Tampak Atas Relieving Platform dan Tiang Cerucuknya

Keterangan gambar,

$$
\begin{array}{ll}
\mathrm{H} & =\text { Tinggi timbunan oprit jembatan }(\mathrm{m}) \\
\mathrm{B} & =\text { Panjang relieving platform }(\mathrm{m}) \\
\mathrm{L} & =\text { Lebar relieving platform }(\mathrm{m}) \\
\mathrm{z} & =\text { Kedalaman tiang-cerucuk }(\mathrm{m}) \\
\mathrm{n} & =\text { Jumlah tiang-cerucuk per-baris (buah) } \\
\mathrm{m} & =\text { Jumlah tiang-cerucuk per-kolom (buah) } \\
\mathrm{X} & =\text { Tebal relieving platform }(\mathrm{m}) \\
\mathrm{S} & =\text { Jarak antar tiang }(\mathrm{m}) \\
\mathrm{D} & =\text { Diameter tiang }(\mathrm{cm})
\end{array}
$$

Tabel 3. Ringkasan Konstruksi D30 Kelas C pada jarak tiang $2,5 \mathrm{D}$

\begin{tabular}{cccccc}
\hline $\begin{array}{c}\mathrm{H} \\
(\mathrm{m})\end{array}$ & $\begin{array}{c}\mathrm{B} \\
(\mathrm{m})\end{array}$ & $\begin{array}{c}\mathrm{L} \\
(\mathrm{m})\end{array}$ & $\begin{array}{c}\mathrm{z} \\
(\mathrm{m})\end{array}$ & $\begin{array}{c}\mathrm{n} \\
(\text { buah })\end{array}$ & $\begin{array}{c}\mathrm{m} \\
(\text { buah })\end{array}$ \\
\hline 4 & 10 & 1,7 & 13 & 2 & 13 \\
6 & 10 & 4,0 & 17 & 5 & 13 \\
8 & 10 & 8,5 & 19 & 11 & 13 \\
10 & 10 & 14,5 & 21 & 19 & 13 \\
12 & 10 & 21,2 & 24 & 28 & 13 \\
\hline
\end{tabular}

Tabel 4. Ringkasan Konstruksi D50 Kelas C pada jarak tiang $2,5 \mathrm{D}$

\begin{tabular}{cccccc}
\hline $\begin{array}{c}\mathrm{H} \\
(\mathrm{m})\end{array}$ & $\begin{array}{c}\mathrm{B} \\
(\mathrm{m})\end{array}$ & $\begin{array}{c}\mathrm{L} \\
(\mathrm{m})\end{array}$ & $\begin{array}{c}\mathrm{z} \\
(\mathrm{m})\end{array}$ & $\begin{array}{c}\mathrm{n} \\
(\text { buah })\end{array}$ & $\begin{array}{c}\mathrm{m} \\
(\text { buah })\end{array}$ \\
\hline 4 & 10,3 & 2,8 & 18 & 2 & 8 \\
6 & 10,3 & 5,3 & 24 & 4 & 8 \\
8 & 10,3 & 11,5 & 25 & 9 & 8 \\
10 & 10,3 & 20,3 & 32 & 16 & 8 \\
12 & 10,3 & 27,8 & 37 & 22 & 8 \\
\hline
\end{tabular}

Tabel 5. Ringkasan Konstruksi D60 Kelas C pada jarak tiang $2,5 \mathrm{D}$

\begin{tabular}{cccccc}
\hline $\begin{array}{c}\mathrm{H} \\
(\mathrm{m})\end{array}$ & $\begin{array}{c}\mathrm{B} \\
(\mathrm{m})\end{array}$ & $\begin{array}{c}\mathrm{L} \\
(\mathrm{m})\end{array}$ & $\begin{array}{c}\mathrm{z} \\
(\mathrm{m})\end{array}$ & $\begin{array}{c}\mathrm{n} \\
(\text { buah })\end{array}$ & $\begin{array}{c}\mathrm{m} \\
(\mathrm{buah})\end{array}$ \\
\hline 4 & 10,8 & 3,3 & 20 & 2 & 7 \\
6 & 10,8 & 6 & 26 & 4 & 7 \\
8 & 10,8 & 12,3 & 32 & 8 & 7 \\
10 & 10,8 & 21,3 & 37 & 14 & 7 \\
12 & 10,8 & 30,3 & 42 & 20 & 7 \\
\hline
\end{tabular}

Tabel 6. Ringkasan Konstruksi D 30 Kelas C pada jarak tiang 3D

\begin{tabular}{cccccc}
\hline $\begin{array}{c}\mathrm{H} \\
(\mathrm{m})\end{array}$ & $\begin{array}{c}\mathrm{B} \\
(\mathrm{m})\end{array}$ & $\begin{array}{c}\mathrm{L} \\
(\mathrm{m})\end{array}$ & $\begin{array}{c}\mathrm{z} \\
(\mathrm{m})\end{array}$ & $\begin{array}{c}\mathrm{n} \\
(\text { buah })\end{array}$ & $\begin{array}{c}\mathrm{m} \\
(\text { buah })\end{array}$ \\
\hline 4 & 10 & 1,8 & 16 & 2 & 11 \\
6 & 10 & 5,4 & 19 & 6 & 11 \\
8 & 10 & 13 & 20 & 14 & 11 \\
10 & 10 & 20,7 & 27 & 23 & 11 \\
12 & 10 & 30,6 & 30 & 34 & 11 \\
\hline
\end{tabular}

Tabel 7. Ringkasan Konstruksi D50 Kelas C pada jarak tiang 3D

\begin{tabular}{cccccc}
\hline $\begin{array}{c}\mathrm{H} \\
(\mathrm{m})\end{array}$ & $\begin{array}{c}\mathrm{B} \\
(\mathrm{m})\end{array}$ & $\begin{array}{c}\mathrm{L} \\
(\mathrm{m})\end{array}$ & $\begin{array}{c}\mathrm{z} \\
(\mathrm{m})\end{array}$ & $\begin{array}{c}\mathrm{n} \\
(\text { buah })\end{array}$ & $\begin{array}{c}\mathrm{m} \\
(\text { buah })\end{array}$ \\
\hline 4 & 10,5 & 3,0 & 21 & 2 & 7 \\
6 & 10,5 & 7,5 & 28 & 5 & 7 \\
8 & 10,5 & 16,5 & 34 & 11 & 7 \\
10 & 10,5 & 28,5 & 40 & 19 & 7 \\
12 & 10,5 & 39,0 & 45 & 26 & 7 \\
\hline
\end{tabular}

Tabel 8. Ringkasan Konstruksi D60 Kelas C pada jarak tiang 3D

\begin{tabular}{cccccc}
\hline $\begin{array}{c}\mathrm{H} \\
(\mathrm{m})\end{array}$ & $\begin{array}{c}\mathrm{B} \\
(\mathrm{m})\end{array}$ & $\begin{array}{c}\mathrm{L} \\
(\mathrm{m})\end{array}$ & $\begin{array}{c}\mathrm{z} \\
(\mathrm{m})\end{array}$ & $\begin{array}{c}\mathrm{n} \\
(\text { buah })\end{array}$ & $\begin{array}{c}\mathrm{m} \\
(\text { buah })\end{array}$ \\
\hline 4 & 10,8 & 3,6 & 24 & 2 & 6 \\
6 & 10,8 & 9 & 33 & 5 & 6 \\
8 & 10,8 & 18 & 40 & 10 & 6 \\
10 & 10,8 & 30,6 & 48 & 17 & 6 \\
12 & 10,8 & 43,2 & 50 & 24 & 6 \\
\hline
\end{tabular}

Catatan: Hasil kedalaman tiang pada penelitian ini dapat digunakan jika kedalaman tanah belum mencapai tanah keras. Jika tanah keras berada pada kedalaman kurang dari kedalaman tiang penelitian, maka pemancangan dilakukan hanya sampai mencapai tanah keras.

Tabel 3 hingga Tabel 8 juga dibuat dalam bentuk grafik untuk mempermudah perencanaan relieving platform dan tiang cerucuknya. Grafik hubungan tersebut dibagi ke dalam 
hubungan antara tinggi timbunan dengan kebutuhan tiangcerucuk dan tinggi timbunan dengan lebar relieving platform seperti berikut:

1. Hubungan antara tinggi timbunan dengan kebutuhan tiang-cerucuk dengan berbagai variasi

Grafik hubungan antara tinggi timbunan dan tiang cerucuk dengan diameter berbeda dapat dilihat pada Gambar 6.

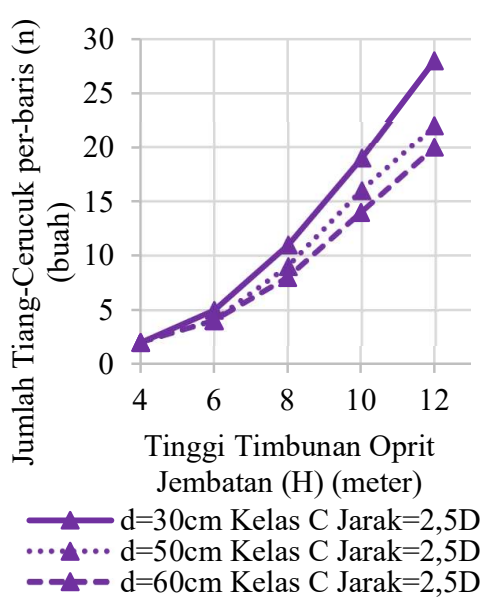

(a)

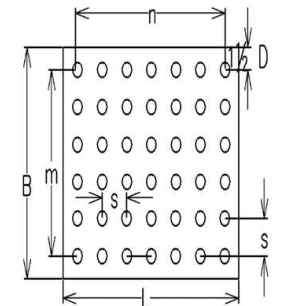

(b)
Gambar 6. (a) Hubungan Antara Tinggi Timbunan Oprit Jembatan (H) dan Jumlah Tiang Cerucuk (n) dengan Jarak yang Sama dan Diameter yang Berbeda; (b) Ilustrasi Tampak Atas Relieving Platform dan Tiang Cerucuknya

Pada Gambar 6, menunjukkan bahwa semakin tinggi timbunan oprit jembatan, maka jumlah tiang-cerucuk akan menghasilkan tiang yang semakin banyak. Selain itu, ukuran diameter juga mempengaruhi kebutuhan tiang pada berbagai ketinggian timbunan oprit jembatan. Hal ini dikarenakan semakin kecil ukuran diameter tiang, maka semakin banyak tiang yang diperlukan untuk menambah kekuatan geser tanah dasar yang berfungsi sebagai tiang-cerucuk. Sedangkan fungsinya sebagai tiang-cerucuk menahan beban aksial, maka semakin kecil ukuran diameter tiang maka $\mathrm{P}_{\mathrm{ijji}} 1$ tiang juga semakin kecil yang menyebabkan kebutuhan menahan beban secara aksial lebih banyak. Hal ini ditunjukkan pada setiap ketinggian timbunan. Namun, pada ketinggian 4 meter, jumlah tiang pada diameter $30 \mathrm{~cm}, 50 \mathrm{~cm}$, dan $60 \mathrm{~cm}$ menunjukkan jumlah tiang yang sama. Hal ini dikarenakan pada perhitungan kebutuhan jumlah tiang pada diameter $50 \mathrm{~cm}$ dan $60 \mathrm{~cm}$ hanya memerlukan 1 tiang. Namun, untuk menghindari pergerakan/defleksi pada saat pemasangan relieving platfrom, maka membutuhkan jumlah tiang yang stabil. Sehingga, kebutuhan jumlah tiang minimum yang diperlukan adalah sebanyak 2 tiang.
Spasi atau jarak antar tiang 2,5D dan 3D menghasilkan kebutuhan yang berbeda pada setiap tipe diameter dan tipe kelas yang sama. Dimana pada jarak 3D menghasilkan kebutuhan jumlah tiang-cerucuk yang lebih banyak daripada jarak 2,5D dalam arah memanjang jalan (longitudinal) seperti yang terlihat pada Gambar 7.

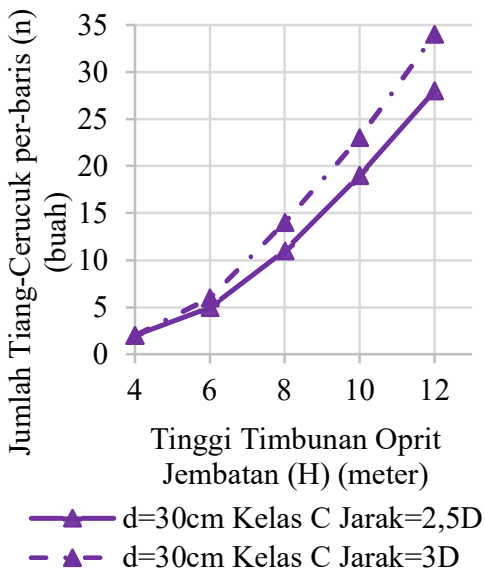

(a)

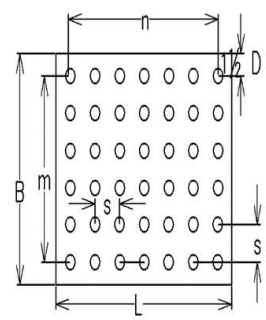

(b)
Gambar 7. (a) Hubungan Antara Tinggi Timbunan Oprit Jembatan $(\mathrm{H})$ dan Jumlah Tiang Cerucuk (n) dengan Diameter yang Sama dan Jarak Antar Tiang Berbeda; (b) Ilustrasi Tampak Atas Relieving Platform dan Tiang Cerucuknya

Hal ini dikarenakan jarak tiang mempengaruhi kebutuhan tiang dalam arah memanjang jalan (longitudinal). Dimana pada saat menghitung kebutuhan tiang-cerucuk dalam menahan overall stability, momen resistance juga harus dikali dengan jarak antar tiang cerucuk yang menyesuaikan jarak pada kebutuhan tiang aksial. Sehingga, jumlah cerucuk arah memanjang jalan (longitudinal) akan menjadi lebih banyak jika jarak tiang yang diperlukan semakin besar. Begitupula pada kebutuhan tiang-cerucuk yang menerima beban aksial. Pada saat menghitung kebutuhan tiang-aksial, beban yang diperhitungkan juga menyesuaikan jarak antar tiang. Oleh karena itu, semakin besar jarak antar tiang, maka kebutuhan tiang akan semakin banyak dalam arah memanjang jalan.

2. Hubungan antara tinggi timbunan dengan kebutuhan lebar relieving platform dengan berbagai variasi

Grafik hubungan antara tinggi timbunan dan lebar relieving platform dengan diameter berbeda dapat dilihat pada Gambar 8.

Berdasarkan Gambar 8, grafik tersebut secara keseluruhan menunjukan semakin tinggi timbunan, maka kebutuhan relieving platform akan semakin lebar. Lebar relieving 
platform yang direncanakan merupakan lebar platform yang mengikuti jumlah kebutuhan tiang pada asumsi menahan beban secara lateral, secara aksial dan tambahan tepi platform minimal selebar $1 \frac{1}{2}$ diameter yang sedang direncanakan. Kebutuhan jumlah tiang-cerucuk pada diameter $60 \mathrm{~cm}$ akan membutuhkan lebar relieving platform lebih banyak daripada kebutuhan diameter $50 \mathrm{~cm}$ dan $30 \mathrm{~cm}$. Hal ini dikarenakan jarak antar tiang pada diameter $30 \mathrm{~cm}, 50 \mathrm{~cm}$. dan $60 \mathrm{~cm}$ berturut-turut menghasilkan lebar relieving platform yang semakin besar. Sehingga, semakin besar diameter tiang yang direncanakan, maka kebutuhan lebar relieving platform juga akan semakin besar.

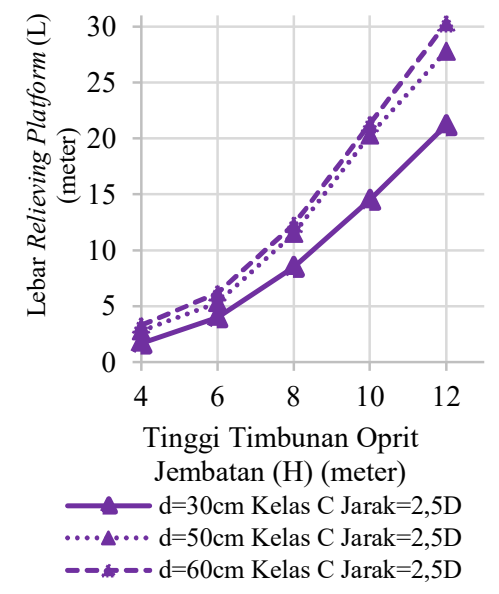

(a)

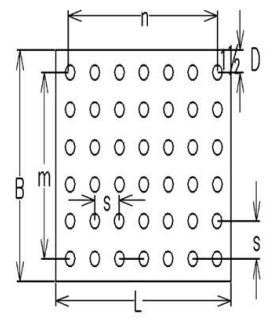

(b)
Gambar 8. (a) Hubungan Antara Tinggi Timbunan Oprit Jembatan (H) dan Lebar Relieving Platform (L) dengan Diameter yang Berbeda dan Jarak Antar Tiang Sama; (b) Ilustrasi Tampak Atas Relieving Platform dan Tiang Cerucuknya

Kebutuhan relieving platform menyesuaikan kebutuhan jumlah tiang-cerucuk, dimana jarak antar tiang 2,5D dan 3D menghasilkan kebutuhan lebar relieving platform yang berbeda pada tipe diameter dan tipe kelas yang sama. Pada Gambar 9, semakin tinggi timbunan oprit jembatan, maka kebutuhan lebar relieving platform pada jarak antar tiang yang berbeda akan semakin besar. Selain itu, semakin besar jarak yang diberikan pada jarak antar tiang, kebutuhan tiangcerucuk akan semakin banyak yang mengakibatkan lebar relieving platform menjadi lebih lebar. Hal ini dikarenakan momen resistance yang dihasilkan oleh program XSTABL tersebut adalah momen resistance untuk tegak lurus gambar per meter, sedangkan jarak antar tiang yang digunakan pada penelitian merupakan 2,5D dan 3D mengikuti kebutuhan jarak antar tiang dalam menahan beban aksial. Oleh karena itu, momen resistance perlu dikali dengan jarak antar tiang sehingga menghasilkan jumlah tiang yang lebih banyak. Hal ini berbanding lurus dengan kebutuhan lebar relieving platformnya. Semakin besar jarak antar tiang, maka kebutuhan jumlah cerucuk semakin banyak dalam arah longitudinal; dan lebar relieving platform akan semakin besar.

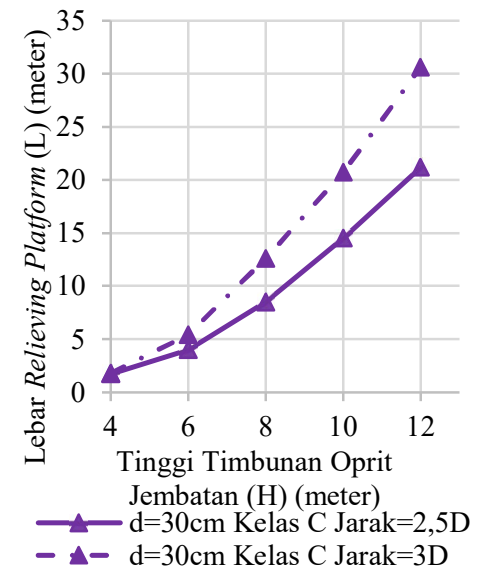

(a)

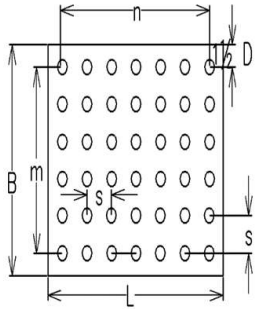

(b)
Gambar 9. (a) Hubungan Antara Tinggi Timbunan (H) dan Lebar Relieving Platform (L) dengan Diameter yang Sama, dan Jarak Antar Tiang Berbeda; (b) Ilustrasi Tampak Atas Relieving Platform dan Tiang Cerucuknya

Analisis Tambahan Biaya Perkuatan Relieving Platform Bersama Tiang Cerucuk

1. Acuan harga tambahan biaya perkuatan

Harga yang digunakan untuk menghitung biaya tambahan optimum pada kebutuhan perkuatan relieving platform dan tiang-cerucuk menggunakan Harga Satuan Pokok Kegiatan (HSPK) Kota Surabaya [12], dan harga spun pile dari WIKA BETON [13],

2. Hasil tambahan biaya perkuatan relieving platform dan tiang cerucuk

Tambahan biaya perkuatan relieving platform dan tiangcerucuk hanya memperhitungkan pemancangan tiang, pekerjaan plat beton bertulang, dan tiang spun pile. Hasil analisis tambahan biaya perkuatan relieving platform dan tiang-cerucuk pada diameter 30 tipe kelas $\mathrm{C}$, dan jarak antar tiang 2,5D dapat dilihat pada Tabel 9. Berdasarkan hasil pada Tabel 9, pada jarak antar tiang 2,5D untuk seluruh ketinggian timbunan oprit jembatan menghasilkan biaya yang lebih murah daripada jarak antar tiang 3D.

Hal ini juga berlaku untuk diameter $50 \mathrm{~cm}$ dan $60 \mathrm{~cm}$. Hasil perhitungan pada jarak antar tiang 2,5D, menghasilkan tambahan biaya yang jauh lebih murah daripada jarak antar tiang 3D. Kondisi ini diakibatkan pada saat memperhitungkan kebutuhan tiang-cerucuk untuk menahan beban lateral, 
momen penahan tambahan (momen resistance) yang didapatkan dari program bantu XSTABL tersebut perlu dikali dengan jarak antar tiang, sehingga semakin besar jarak antar tiang maka kebutuhan tiang akan semakin banyak. Kebutuhan jumlah tiang tersebut juga disesuaikan untuk dapat menahan beban aksial dengan lebar relieving platform yang sama. Selain itu, diameter yang lebih besar akan menghasilkan kebutuhan relieving platform yang lebih lebar pula; dan dari segi biaya, diameter yang lebih besar memiliki biaya yang jauh lebih mahal. Tabel 10 merupakan hasil tambahan biaya pada diameter 50 kelas $\mathrm{C}$ jarak 2,5D dan 3D sedangkan Tabel 11 merupakan hasil tambahan biaya pada diameter 60 kelas $\mathrm{C}$ pada jarak 2,5D dan 3D.

Tabel 9. Hasil Tambahan Biaya D 30 Kelas C Pada Jarak $2,5 \mathrm{D} \& 3 \mathrm{D}$

\begin{tabular}{ccc}
\hline $\begin{array}{c}\mathrm{H} \\
(\mathrm{m})\end{array}$ & $\begin{array}{c}\text { D30 Kelas C 2,5D } \\
\text { Total Biaya Optimal }\end{array}$ & $\begin{array}{c}\text { D30 Kelas C 3D } \\
\text { Total Biaya Optimal }\end{array}$ \\
\hline 4 & Rp222.374.419 & Rp234.555.481 \\
6 & Rp706.620.400 & Rp806.100.306 \\
8 & Rp1.699.356.967 & Rp1.969.872.058 \\
10 & Rp3.221.925.067 & Rp4.287.724.837 \\
12 & Rp5.393.975.932 & Rp6.944.707.638 \\
\hline
\end{tabular}

Tabel 10. Hasil Tambahan Biaya D 50 Kelas C Pada Jarak 2,5D \& 3D

\begin{tabular}{ccc}
\hline $\begin{array}{c}\mathrm{H} \\
(\mathrm{m})\end{array}$ & $\begin{array}{c}\text { D50 Kelas C 2,5D } \\
\text { Total Biaya Optimal }\end{array}$ & $\begin{array}{c}\text { D50 Kelas C 3D } \\
\text { Total Biaya Optimal }\end{array}$ \\
\hline 4 & Rp350.780.832 & Rp363.635.542 \\
6 & Rp885.211.741 & Rp1.145.589.174 \\
8 & Rp2.007.731.492 & Rp2.980.480.214 \\
10 & Rp4.502.366.921 & Rp5.902.533.516 \\
12 & Rp7.075.593.984 & Rp8.995.100.888 \\
\hline
\end{tabular}

Tabel 11. Hasil Tambahan Biaya D 60 Kelas C Pada Jarak 2,5D \& 3D

\begin{tabular}{ccc}
\hline $\begin{array}{c}\mathrm{H} \\
(\mathrm{m})\end{array}$ & $\begin{array}{c}\text { D60 Kelas C 2,5D } \\
\text { Total Biaya Optimal }\end{array}$ & $\begin{array}{c}\text { D60 Kelas C 3D } \\
\text { Total Biaya Optimal }\end{array}$ \\
\hline 4 & Rp449.495.926 & Rp461.500.649 \\
6 & Rp1.101.685.535 & Rp1.458.842.471 \\
8 & Rp2.601.105.456 & Rp3.441.969.806 \\
10 & Rp5.173.121.950 & Rp6.868.685.247 \\
12 & Rp8.208.848.395 & Rp9.981.147.375 \\
\hline
\end{tabular}

Berdasarkan hasil perhitungan tambahan biaya perkuatan relieving platform dan tiang-cerucuk, semakin tinggi timbunan maka biaya yang akan diperlukan akan semakin banyak pula. Hal ini berlaku untuk keseluruhan tipe diameter tiang dan variasi jarak antar tiang. Pada diameter tiang $30 \mathrm{~cm}$, walaupun menghasilkan jumlah kebutuhan tiang yang lebih banyak daripada diameter $50 \mathrm{~cm}$ dan $60 \mathrm{~cm}$; namun dari segi biaya menghasilkan biaya yang jauh lebih murah daripada diameter $50 \mathrm{~cm}$ dan $60 \mathrm{~cm}$. Biaya termurah berturut-turut berada pada diameter $30 \mathrm{~cm}, 50 \mathrm{~cm}$, dan $60 \mathrm{~cm}$. Hal ini menunjukkan bahwa walaupun dari segi teknis tipe diameter 60 $\mathrm{cm}$ kelas $\mathrm{C}$ merupakan variasi yang lebih sedikit namun dari segi biaya, diameter $60 \mathrm{~cm}$ memerlukan biaya yang jauh lebih besar daripada tipe diameter $30 \mathrm{~cm}$ dan $50 \mathrm{~cm}$. Diameter $30 \mathrm{~cm}$ menghasilkan total biaya yang paling murah dikarenakan harga pile pada diameter $30 \mathrm{~cm}$ lebih murah hampir tiga kali harga diameter $60 \mathrm{~cm}$. Selain itu jarak antar tiang juga mempengaruhi biaya tambahan pada masingmasing perkuatan. Pada analisis kebutuhan jumlah tiang, semakin besar jarak yang direncanakan maka kebutuhan akan relieving platform dan tiang cerucuk akan semakin besar. Sehinggakebutuhan tambahan biaya perkuatan pada jarak antar tiang 3D menghasilkan biaya yang lebih mahal dari jarak antar tiang 2,5D. Jika lebih memperhatikan segi efisiensi, maka perencanaan pada diameter $30 \mathrm{~cm}$ dengan jarak 2,5D merupakan sistem yang paling efektif.

\section{Simpulan}

Tiang cerucuk yang dibutuhkan untuk menahan beban oprit jembatan secara aksial memiliki jumlah yang bervariasi tergantung ketinggian oprit, lebar relieving platform dan beban aksial yang diterima oleh tiang. Jumlah tiang yang diperlukan untuk menahan beban aksial pada berbagai variasi timbunan harus menghasilkan jumlah yang sama pada asumsi menahan overall stability.

Kebutuhan jumlah tiang-cerucuk dan lebar relieving platform dipengaruhi oleh ukuran diameter tiang. Semakin kecil ukuran diameter tiang, maka semakin banyak tiang yang diperlukan untuk menambah kekuatan geser tanah dasar yang berfungsi sebagai tiang-cerucuk. Selain itu, semaka semakin kecil ukuran diameter tiang maka $\mathrm{P}_{\mathrm{ijin}} 1$ tiang juga semakin kecil yang menyebabkan kebutuhan menahan beban secara aksial lebih banyak.

Jarak antar tiang juga mempengaruhi kebutuhan jumlah tiang-cerucuk dan lebar relieving platform. Semakin besar jarak antar tiang, maka kebutuhan jumlah tiang dan lebar relieving platform semakin besar. Hal ini dikarenakan jarak tiang mempengaruhi kebutuhan tiang pada kebutuhan menahan beban lateral dan aksial. 
Berdasarkan variasi diameter dan jarak antar tiang, keseluruhan variasi tersebut dapat dilakukan di lapangan. Namun, sistem relieving platform dan tiang cerucuk yang paling efektif adalah pada diameter $30 \mathrm{~cm}$ dengan jarak antar tiang 2,5D. Hal ini dikarenakan harga yang dibutuhkan untuk perencanaan pada diameter $30 \mathrm{~cm}$ dengan jarak antar tiang 2,5D tersebut menghasilkan biaya yang jauh lebih murah. Sehingga selain efektif mengatasi permasalahan pada abutment jembatan, variasi tersebut juga menghasilkan biaya yang jauh lebih murah dan dapat diaplikasikan langsung di lapangan.

\section{Daftar Pustaka}

[1] I. B. Mochtar, Metode Perencanaan Alternatif untuk Pembangunan Jalan dan Oprit Jembatan di Atas Tanah yang Lunak, Surabaya, 2000.

[2] S. Sarita dan S. Gupta, "Optimization of Reinforced Concrete Retaining Walls of Varying Heights Using Relieving Platform," International Journal of Engineering Research Technology (IJERT), vol. IV, no. 06, pp. 1071-1077, 2015.

[3] D. Dhamdhere, V. Rathi dan P. Kolase, "Design and Analysis of Retaining Wall," International Journal of Management, Technology and Engineering, vol. VIII, no. 9, pp. 1246-1263, 2018.

[4] C. V. P, Foundation Engineering, New Delhi: PHI Learning Private Limited, 2012.

[5] R. A. Septiandri, I. B. Mochtar dan Y. Lastiasih, "Metode Cepat untuk Menentukan Besar Pemampatan Konsolidasi (Sc) Timbunan di Atas Tanah Lunak dan Perencanaan Perkuatannya untuk
Kondisi dengan dan Tanpa Pemasangan Prefabricated Vertical Drain (PVD)", Surabaya: Thesis Departemen Teknik Sipil FTSP - Institut Teknologi Sepuluh Nopember, 2021.

[6] N. E. Mochtar, Modul Ajar Metode Perbaikan Tanah, Surabaya: ITS Press, 2012.

[7] "SNI 8460-2017 Persyaratan Perancangan Geoteknik," Badan Standarisasi Nasional, Jakarta, 2017.

[8] M. D. Ardana dan I. B. Mochtar, "Pengaruh Tegangan Overburden Efektif dan Plastisitas Tanah terhadap Kekuatan Geser Undrained Tanah Lempung Berkonsistensi Sangat Lunak Sampai Kaku yang Terkonsolidasi Normal", Surabaya: Thesis Jurusan Teknik Sipil FTSP - Institut Teknologi Sepuluh Nopember, 1999.

[9] I. B. Mochtar, "Parameter Empiris untuk Tanah Lunak di Lapangan,” Jurusan Teknik Sipil Institut Teknologi Sepuluh Nopember, Surabaya, 2001.

[10] I. W. Arya dan I. B. Mochtar, "Pengaruh Penambahan Cerucuk Terhadap Peningkatan Kuat Geser Tanah Lunak Pada Pemodelan di Laboratorium", Surabaya: Thesis Jurusan Teknik Sipil FTSP-Institut Teknologi Sepuluh Nopember, 2002.

[11] J. E. Bowles, Analisis dan Desain Pondasi Jilid 2, Jakarta: Erlangga, 1998.

[12] "Harga Satuan Pokok Kegiatan 2018," Pemerintah Kota Surabaya, Surabaya, 2018.

[13] "Harga Spun Pile dan Spesifikasi Tiang," WIKA BETON, Surabaya, 2021. 


\section{Halaman ini sengaja dikosongkan}

